\title{
Finite element modeling of the shaped charge jet and design of the reusable perforating gun
}

\author{
Zhao Zhang ${ }^{1} \cdot$ Wei-Wei Jin ${ }^{1,2}$
}

Received: 20 December 2019 / Published online: 4 June 2020

(c) The Author(s) 2020

\begin{abstract}
Finite element method is used to study the formations of the penetration jet, the bulge, and the burr in the designed reusable perforating gun. The attached layer of the soft metal on the perforator is studied for the controlling of the bulge height on the casing of the reusable perforating gun. Results indicate that the shaped charge jet is initially formed in the center of the shaped charge liner and then the material of the liner is driven to the centerline of the liner by the detonation wave. The attachment of the soft metal layer to the cartridge of the perforator can be beneficial to control the bulge height. The design on the blind holes on the casing can affect the burr height formed by the collision between the jet and the casing. With the increase in the liner angle, the penetration width on the cement wall of the wellbore is increased.
\end{abstract}

Keywords Perforating gun $\cdot$ Finite element method $\cdot$ Bulge $\cdot$ Burr

\section{List of symbols}

$\begin{array}{ll}A & \text { Material constant } \\ B & \text { Material constant } \\ c & \text { Material constant } \\ n & \text { Material constant } \\ m & \text { Material constant } \\ \sigma_{\mathrm{y}} & \text { Stress } \\ \bar{\varepsilon}^{\mathrm{pl}} & \text { Effective plastic strain } \\ \dot{\varepsilon} & \text { Effective total strain rate normalized by quasi-static } \\ & \text { threshold rate } \\ T^{*} & \text { Homologous temperature } \\ T_{\mathrm{a}} & \text { Ambient temperature } \\ T_{\mathrm{m}} & \text { Melting temperature } \\ \dot{\bar{\varepsilon}}_{\mathrm{p}} & \text { Effective total strain rate } \\ \dot{\varepsilon}_{0} & \text { Quasi-static threshold rate } \\ P & \text { Pressure } \\ V & \text { Volume of the charge }\end{array}$

Edited by Xiu-Qiu Peng

\section{Zhao Zhang}

zhangz@dlut.edu.cn

1 State Key Laboratory of Structural Analysis for Industrial Equipment, Department of Engineering Mechanics, Faculty of Vehicle Engineering and Mechanics, Dalian University of Technology, Dalian 116024, China

2 Institute of Manned Space System Engineering, China Academy of Space Technology, Beijing 100094, China
$E \quad$ Initial ratio of internal energy

$A_{1} \quad$ Material constant

$B_{1} \quad$ Material constant

$\omega \quad$ Material constant

$R_{1} \quad$ Material constant

$R_{2} \quad$ Material constant

$C$ The intercept of $v_{\mathrm{s}}-v_{\mathrm{p}}$ curve

$S_{1} \quad$ Coefficient of the slope of the $v_{\mathrm{s}}-v_{\mathrm{p}}$ curve

$S_{2} \quad$ Coefficient of the slope of the $v_{\mathrm{s}}-v_{\mathrm{p}}$ curve

$S_{3} \quad$ Coefficient of the slope of the $v_{\mathrm{s}}-v_{\mathrm{p}}$ curve

$v_{\mathrm{s}} \quad$ Shear wave speed

$v_{\mathrm{p}} \quad$ Compressive wave speed

$\gamma_{0} \quad$ Gruneisen gamma

a First-order volume correction to $\gamma_{0}$

$\rho_{0} \quad$ Initial density

$\rho \quad$ Density

$\mu \quad$ Volumetric parameter

$K \quad$ Tangent modulus

$\sigma_{\mathrm{s}} \quad$ Yield stress

$g \quad$ Flow potential

$\mathrm{d} \lambda \quad$ Plastic state parameter

$\sigma_{0} \quad$ Initial yield stress

$C$ Cowper-Symonds parameter

$P \quad$ Cowper-Symonds parameter

$\beta \quad$ Hardening parameter

$E_{\mathrm{p}} \quad$ Plastic hardening modulus

$E_{\text {tan }}$ Tangent modulus

$E_{\mathrm{W}}$ External work 


$\begin{array}{ll}E_{\mathrm{K}} & \text { Kinematic energy } \\ E_{\mathrm{U}} & \text { Internal energy } \\ E_{\mathrm{F}} & \text { Frictional energy } \\ E_{\mathrm{V}} & \text { Dissipated viscous energy } \\ E_{\mathrm{I}} & \text { Remaining energy } \\ \sigma_{\mathrm{c}} & \text { Stress without viscous dissipation effect } \\ \sigma_{v} & \text { Viscous stress } \\ \varepsilon^{\mathrm{e}} & \text { Elastic strain } \\ \varepsilon^{\mathrm{p}} & \text { Plastic strain } \\ \varepsilon^{\mathrm{c}} & \text { Creep strain } \\ W & \text { Penetration width } \\ v & \text { Maximum jet velocity }\end{array}$

\section{Introduction}

Perforation is very important in the petroleum well completions. The perforation quality can directly affect the oil productivity. For perforation with high quality, different models have been proposed to predict the productivity of the perforated well or the permeability around the tunnel (Gambirasio et al. 2017; Hagoot 2007; Karacan and Halleck 2003; Du et al. 2017; Wang et al. 2010). Perforation by shooting with shaped charge is now commonly used in well completions due to its low cost and high efficiency. In the perforating process, a perforator is exploded to form a jet, which can penetrate the casing, the cement and the rock. The maximum velocity of the jet can reach $8000 \mathrm{~m} / \mathrm{s}$ in some cases. Experiment shows the strength of the target can be treated as a factor for the penetration by the metallic jet in the perforating process (Eichelberger 1956). The perforating processes with shaped charge can be studied by both numerical simulation and experiment (Guo et al. 2011; Lee 2002; Molinari 2002; Murphy et al. 2003). A practical method was proposed to accurately predict the perforation depth and the size of the perforation hole (Ott et al. 1994). The shaped charge liner is one of the key components in the perforator, which serves as the basis for the jet formation (Xu et al. 2019; Guo et al. 2019; Eichelberger and Pugh 1952). The theory of the shaped charge formation, the steady-state and the quasi-steady-state theories of the jet formation and the target penetration were proposed (Eichelberger 1956; Eichelberger and Pugh 1952; Birkhoff et al. 1948). In jet formation, the liner material undergoes huge stretching deformations in the axial direction. When the liner material impacts on the charge axis, it ceases to move in the radial direction (Shvetsov et al. 2011). The penetration process and the destruction mechanism of concrete targets by the shaped charges and kinetic energy projectiles were analyzed (Wang et al. 2008). It was found that the shaped charge directly affects the penetration into the target and causes very large spalling area in comparison with the kinetic energy projectile. The liner collapsing and jet/slug formation of the double-layer shaped charge were analyzed for the improvement of the shaped charge performance (Zhang and Qiao 2011). It has been considered that the shaped charge with an axial channel can be beneficial to the composite shaped charge of the "base-head" type (Malygin et al. 2011).

The schematic of the perforating processes is shown in Fig. 1. The jet driven by the explosion can form a hole on

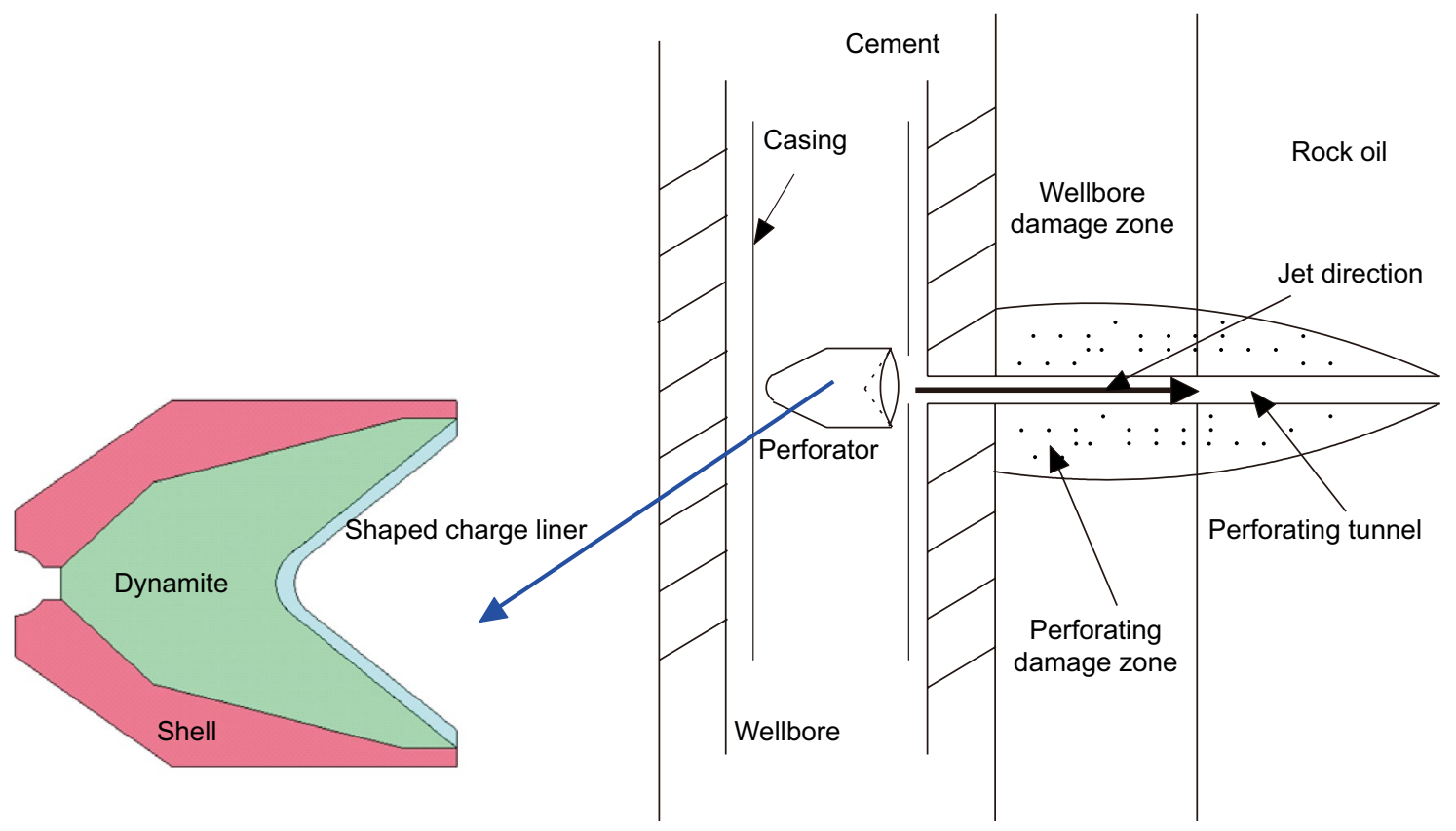

Fig. 1 Schematic of the perforating process 
the cement and the rock oil. Due to the pressure in the rock oil, the oil can flow into the perforating tunnel and enter into the wellbore. At the same time, the cartridge can move in the opposite direction and collide on the casing of the perforating gun. Usually, there are blind holes on the casing to reduce the resistance to the jet. Thin wall tubulars with $D / t=7 \sim 15$ are usually used for downhole perforating in well completion (Zhao et al. 2017). When the jet penetrates the casing, burr is formed on the blind holes on the casing. Meanwhile, the cartridge moves in the opposite direction and collide the casing. Bulge can be formed in this collision, which can affect the reuse of the perforating gun.

The burr height can affect the reuse of the perforating gun. But till now, the relations between the burr height and the perforating gun have seldom been studied. To reuse the perforating gun, the collision between the cartridge and the casing of the perforating gun also needs to be studied to control the bulge height on the shell. The formations of penetration jet, the bulge and the burr need to be studied as well as the attachment of soft metal layer to reveal the controlling of the bulge and burr heights in the reusable perforating gun.

\section{Model description}

\subsection{Model of shaped charge liner}

The DP36RDX25-2 perforating gun is selected for simulation. The outer diameter of the casing is $154 \mathrm{~mm}$ and the inner diameter $132 \mathrm{~mm}$. The material of the casing is 40CrNiMo. The yield stress of $40 \mathrm{CrNiMo}$ is taken as $888 \mathrm{MPa}$. The strength limit is $1043 \mathrm{MPa}$. The elongation is $12.7 \%$. The shaped charge liner is made by copper. The density of the copper is $8932 \mathrm{~kg} / \mathrm{m}^{3}$. The thickness of the shaped charge liner is $1.5 \mathrm{~mm}$. The charge height is $16 \mathrm{~mm}$. Johnson-Cook constitutive model (Mareau 2020) is used for the description of the mechanical behavior of shaped charge liner,

$\sigma_{\mathrm{y}}=\left(A+B \bar{\varepsilon}^{\mathrm{p} n}\right)(1+c \ln \dot{\varepsilon})\left(1-\left(T^{*}\right)^{m}\right)$

where $A, B, c, n$ and $m$ are material constants, as shown in Table 1.
$T^{*}=\frac{T-T_{\mathrm{a}}}{T_{\mathrm{m}}-T_{\mathrm{a}}}$

$\dot{\varepsilon}^{*}=\dot{\bar{\varepsilon}}_{\mathrm{p}} / \dot{\varepsilon}_{0}$

$T_{\mathrm{a}}$ and $T_{\mathrm{m}}$ represent the ambient and the melting temperatures.

\subsection{Description of explosive}

The Jones-Wilkins-Lee (JWL) equation is used for the calculation of explosion (Yu et al. 1999; Yan et al. 2020),

$P=A_{1}\left(1-\frac{\omega}{R_{1} V}\right) \mathrm{e}^{-R_{1} V}+B_{1}\left(1-\frac{\omega}{R_{2} V}\right) \mathrm{e}^{-R_{2} V}+\frac{\omega E}{V}$

where $V$ is the volume of the charge, $E$ is the initial ratio of internal energy and $A_{1}, B_{1}, \omega, R_{1}$ and $R_{2}$ are material constants. $32 \mathrm{~g}$ RDX is used as explosive for the perforating shaped charge in DP36RDX25-2 perforating gun. The parameters for RDX are indicated in Table 2.

\subsection{Equation of state}

Gruneisen state equation is used to describe the dynamic responses,

$P=\frac{\rho_{0} C^{2} \mu\left[1+\left(1-\frac{\gamma_{0}}{2}\right) \mu-\frac{a}{2} \mu^{2}\right]}{\left[1-\left(S_{1}-1\right) \mu-S_{2} \frac{\mu^{2}}{\mu+1}-S_{3} \frac{\mu^{3}}{(\mu+1)^{2}}\right]^{2}}+\left(\gamma_{0}+a \mu\right) E$

where $C$ is the intercept of $v_{\mathrm{s}}-v_{\mathrm{p}}$ curve (shear and compressive wave speeds) (Meyers 1994). $S_{1}, S_{2}$ and $S_{3}$ are the coefficients of the slope of the $v_{\mathrm{s}}-v_{\mathrm{p}}$ curve. $\gamma_{0}$ is the Gruneisen gamma. $a$ is the first-order volume correction to $\gamma_{0}$ and $\mu=\rho / \rho_{0}-1$. The parameters for shaped charge liner and air are listed in Tables 3 and 4, respectively.

Table 1 Parameters in Johnson-Cook model

\begin{tabular}{lllllll}
\hline$A$ & $B$ & $C$ & $n$ & $m$ & $T_{\mathrm{a}}, \mathrm{K}$ & $T_{\mathrm{m}}, \mathrm{K}$ \\
\hline $0.90 \mathrm{E}-03$ & $0.29 \mathrm{E}-02$ & 0.31 & 0.025 & 1.09 & 1360 & 293.0 \\
\hline
\end{tabular}

Table 2 Parameters for RDX

\begin{tabular}{lllllllll}
\hline$\rho, \mathrm{g} / \mathrm{cm}^{3}$ & $D, \mathrm{~cm} / \mu \mathrm{s}$ & $P, \mathrm{GPa}$ & $A, \mathrm{GPa}$ & $B, \mathrm{GPa}$ & $R_{1}$ & $R_{2}$ & $\omega$ & $E$ \\
\hline 1.640 & 0.6930 & 27.0 & 374.0 & 3.230 & 4.150 & 0.950 & 0.30 & 0.07 \\
\hline
\end{tabular}


Table 3 Parameters in Gruneisen state equation for shaped charge liner (copper)

\begin{tabular}{llllll}
\hline$C$ & $S_{1}$ & $S_{2}$ & $S_{3}$ & $\gamma_{0}$ & $a$ \\
\hline 0.394 & 1.49 & 0.00 & 0.00 & 1.99 & 0.0 \\
\hline
\end{tabular}

Table 4 Parameters in Gruneisen state equation for air

\begin{tabular}{llllll}
\hline$C$ & $S_{1}$ & $S_{2}$ & $S_{3}$ & $\gamma_{0}$ & $a$ \\
\hline 0.034 & 0.00 & 0.00 & 0.00 & 1.40 & 0.0
\end{tabular}

\subsection{ALE and adaptive re-meshing}

To avoid mesh distortions and entanglements, arbitrary Lagrangian-Eulerian (ALE) mesh or adaptive re-meshing can be used (Wan et al. 2017; Zhang and Tan 2019; Zhang et al. 2017; Zhang and Zhang 2014). In the procedure of ALE, one or more time-step computations are conducted. Meshes are deforming with the flow of the material. When the deformation is completed, the meshes maintain the boundary condition of the object, and the internal meshes need to be updated. This step is called as smooth step. Then, the advection step is taken to transport the unit variables (density, energy, stress tensor, etc.) and the velocity vectors of nodes to the new updated meshes. The problem can be finally solved with the conservation equation. The meshes in the solution process to the adaptive re-meshing of the deformed jet at different time are shown in Fig. 2. Due to the use of adaptive re-meshing technique, mesh sensitivity problem can be avoided. The number of the elements variates from 3680 in Fig. 2a to 19,912 in Fig. 2b and then 19,906 in Fig. 2c at different time.

\subsection{Models of perforator and casing}

Figure 3 shows the perforator and the casing system. The outer diameter of the casing is $154 \mathrm{~mm}$ and the inner diameter $132 \mathrm{~mm}$. The thickness of the casing is $11.0 \mathrm{~mm}$. The length of the casing is $1213 \mathrm{~mm}$. The material of the casing is 40CrNiMo. The thickness of the shaped charge liner made in copper is $1.5 \mathrm{~mm}$. The charge height is $16 \mathrm{~mm}$. The thickness of the attached soft metal is $8 \mathrm{~mm}$. Dynamite and shaped charge liner exist in the shell as indicated in Fig. 1. Due to the characteristics of high ductility, aluminum and magnesium alloys are selected to be the attached soft metal.

The strain hardening constitutive model of the casing is shown as:

$\sigma=\sigma_{\mathrm{s}}+K \bar{\varepsilon}^{\mathrm{pl}}$

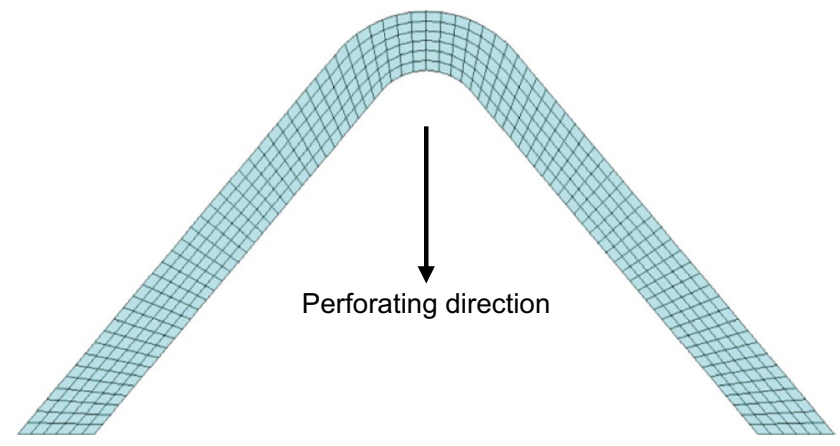

(a) $t=0 \mu \mathrm{s}$

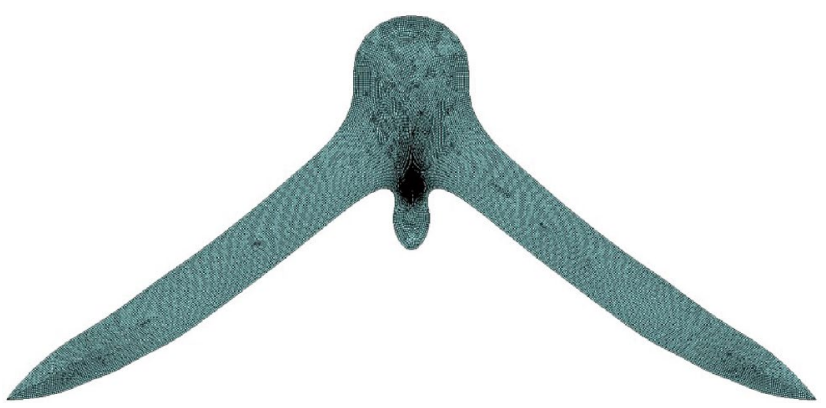

(b) $t=6 \mu \mathrm{s}$

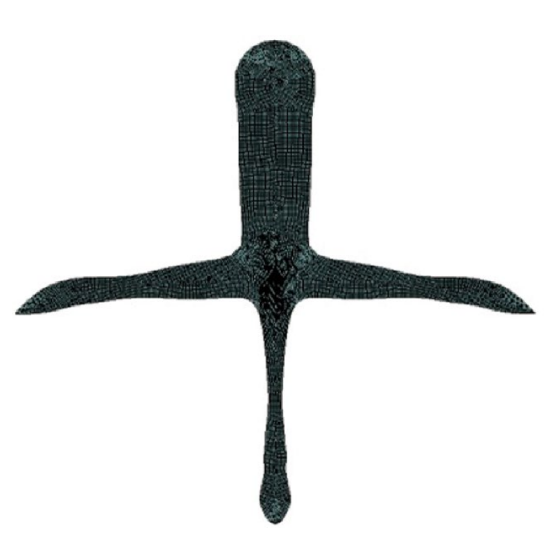

(c) $t=12 \mu \mathrm{s}$

Fig. 2 Meshes of the shaped charge liner in solution process

where $K$ is the tangent modulus and $\bar{\varepsilon}^{\mathrm{pl}}$ is the equivalent plastic strain. When the equivalent stress reaches the strength limit, the casing is broken by the jet.

For the associated plastic flow, the flow rule can be expressed as:

$\mathrm{d} \varepsilon^{\mathrm{pl}}=\mathrm{d} \lambda \frac{\partial g}{\partial \sigma}$

where $g$ is the flow potential. $\mathrm{d} \lambda$ is the plastic state parameter.

The Cowper-Symonds model is used for the description of the material behavior of the cement, 

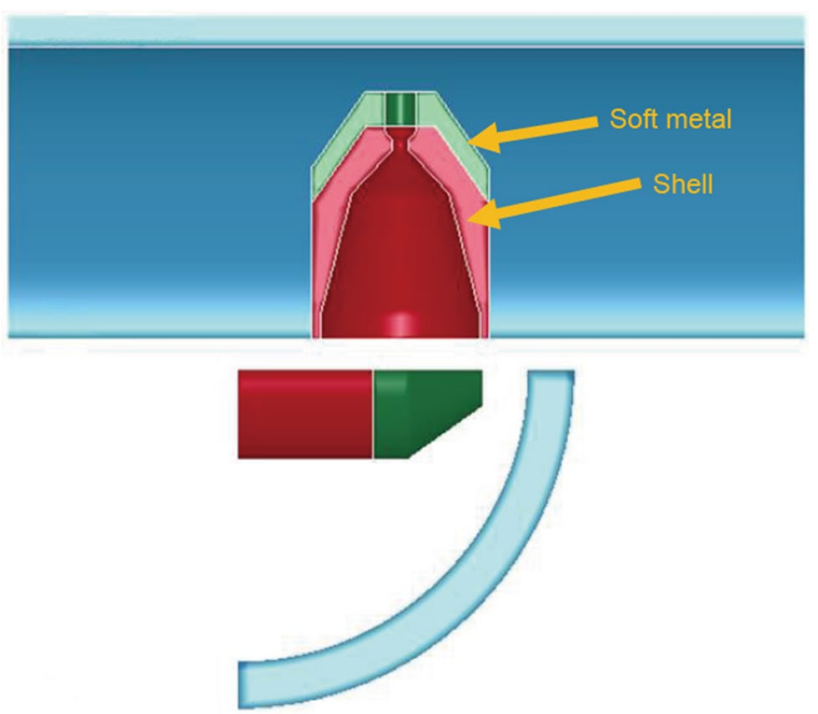

Fig. 3 Perforator with attachment of soft metal

Table 5 Parameters of cement

\begin{tabular}{llllll}
\hline $\begin{array}{l}\text { Density } \\
\rho, \mathrm{g} / \mathrm{cm}^{3}\end{array}$ & $\begin{array}{l}\text { Elastic } \\
\text { modulus } \\
E, \mathrm{GPa}\end{array}$ & $\begin{array}{l}\text { Poisson } \\
\text { ratio } \gamma\end{array}$ & $\begin{array}{l}\text { Yield } \\
\text { stress } \sigma_{0}, \\
\mathrm{MPa}\end{array}$ & $\begin{array}{l}\text { Tangent } \\
\text { modulus } \\
E_{\text {tan }}, \mathrm{GPa}\end{array}$ & $\begin{array}{l}\text { Hardening } \\
\text { param- } \\
\text { eter } \beta\end{array}$ \\
\hline 2.65 & 40 & 0.3 & 100 & 0.04 & 0.5 \\
\hline
\end{tabular}

$\sigma_{\mathrm{y}}=\left[1+\left(\frac{\dot{\varepsilon}}{C}\right)^{\frac{1}{P}}\right]\left(\sigma_{0}+\beta E_{\mathrm{p}} \bar{\varepsilon}_{\mathrm{p}}\right)$

where $\sigma_{0}$ is the initial yield stress. $C$ and $P$ are the Cowper-Symonds parameters. $\beta$ is the hardening parameter. $E_{\mathrm{p}}$ is the plastic hardening modulus,

$E_{\mathrm{p}}=\frac{E_{\mathrm{tan}} E}{E-E_{\mathrm{tan}}}$

where $E_{\tan }$ is the tangent modulus.

The values of the above-mentioned parameters are listed in Table 5. 0.1 is taken to be the erosion strain for failure of cement in simulation.

According to the energy balance, the external work can be converted to kinematic energy, internal energy and frictional energy,

$E_{\mathrm{W}}=E_{\mathrm{K}}+E_{\mathrm{U}}+E_{\mathrm{F}}$

$E_{\mathrm{F}}=\int_{0}^{t} \iint_{S} p_{t} \cdot \dot{\gamma} \mathrm{d} S \mathrm{~d} t$
$E_{\mathrm{K}}=\iiint_{V} \frac{1}{2} \rho \mathbf{v} \cdot \mathbf{v d} V$

Due to the short time for penetration, the integral in Eq. (11) must be very small and can be neglected. The frictional energy is small and nearly to be zero. The dissipated portions of internal energy $E_{\mathrm{U}}$ are split off into the energy by dissipated viscous effect $E_{\mathrm{V}}$ and the remaining energy $E_{\mathrm{I}}$,

$$
\begin{aligned}
& E_{\mathrm{V}}=\int_{0}^{t}\left(\int_{V} \sigma_{\mathrm{v}}: \dot{\varepsilon} \mathrm{d} V\right) \mathrm{d} \tau \\
& E_{\mathrm{I}}=\int_{0}^{t}\left(\int_{V} \sigma_{\mathrm{c}}: \dot{\varepsilon} \mathrm{d} V\right) \mathrm{d} \tau
\end{aligned}
$$

where $\sigma_{\mathrm{c}}$ is the stress without viscous dissipation effect. $\sigma_{\mathrm{v}}$ is the viscous stress. The internal energy includes the elastic strain energy, the energy dissipated by plasticity and the energy dissipated by time-dependent deformation,

$$
\begin{aligned}
E_{\mathrm{I}}= & \int_{0}^{t}\left(\int_{V} \sigma_{\mathrm{c}}: \dot{\varepsilon}^{\mathrm{e}} \mathrm{d} V\right) \mathrm{d} \tau+\int_{0}^{t}\left(\int_{V} \sigma_{\mathrm{c}}: \dot{\varepsilon}^{\mathrm{p}} \mathrm{d} V\right) \mathrm{d} \tau \\
& +\int_{0}^{t}\left(\int_{V} \sigma_{\mathrm{c}}: \dot{\varepsilon}^{\mathrm{c}} \mathrm{d} V\right) \mathrm{d} \tau
\end{aligned}
$$

where $\varepsilon^{\mathrm{e}}$ is the elastic strain, $\varepsilon^{\mathrm{p}}$ plastic strain and $\varepsilon^{\mathrm{c}}$ the creep strain.

LS-DYNA was used for the simulations of the jet formation, the collision between the cartridge and the casing and the casing and collision between the jet and the concrete. ABAQUS was used for the simulation of the collision between the jet and the casing.

\section{Results and discussions}

Figure 4 shows the velocity of the jet. The jet is initially formed in the center of the shaped charge liner, and then, the material of the liner is driven to the centerline of the liner by the detonation wave. The jet is divided into two parts: the head and the body. The velocity of the jet head is higher and can be increased to $4115 \mathrm{~m} / \mathrm{s}$ in a short time when the liner angle is $80^{\circ}$. About $7 \mu \mathrm{s}$ after the explosion, the jet velocity can reach the maximum value and then remains in this high speed until the jet penetrates the casing and the cement. The computational result is similar to the experimental and numerical figures on jet formation (Elshenawy and Li 2013). 


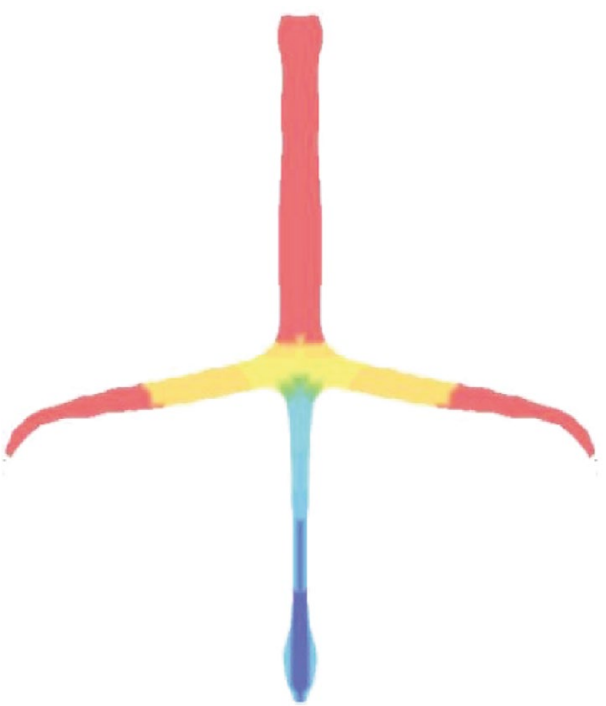

$\mathrm{Vy}, \mathrm{m} / \mathrm{s}$
$611.9-$
$962.2-$
$1312.0-$
$1663.0-$
$2013.0-$
$2363.0-$
$2714.0-$
$3064.0-$
$3414.0-$
$3761.0-$
4115.0

Fig. 4 Velocity of the jet

The velocity of the cartridge can reach $150 \mathrm{~m} / \mathrm{s}$. Due to the fact that there is no restriction for the movements in the axial direction, the cartridge can collide the casing after the detonation. Then, a bulge can be formed on the surface of the casing. Figures 5, 6, 7, 8 and 9 reveal the collision between cartridge and the casing in different cases without attached layer, with attached layer of AA6061 and with attached layer of AZ80A-T5 magnesium alloy. It can be seen that the attachment of the layer of soft metal can provide good energy dissipations. The metal layer can dissipate the kinetic energy of the perforator by deformations, which can lead to the decrease in the bulge height. The provided relationship between the yield strength and the formed bulge height can be helpful for the selection of attached soft metal in the design of reusable perforating gun.

The collision between the cartridge and the casing without soft metal is shown in Fig. 5. The annular and longitudinal stresses on the casing are similar. This phenomenon was also observed by experiment (Dou et al. 2019). The maximum effective strain on the casing is 0.67 , and the maximum on the cartridge is 0.39 . The dissipated plastic energy is dependent on the stress and the corresponding strain. So, the increase in the plastic deformation of the cartridge can be beneficial to the dissipation of energy on the cartridge. Meanwhile, the energy dissipated to the casing becomes smaller. This can protect the casing for the reuse of the perforating gun.

When the cartridge is attached by the layer of soft metal, the soft metal can be broken, which can be beneficial to the decreases of the bulge height. When a layer of AA6061 aluminum alloy is attached on the cartridge, as shown in Fig. 6, the effective strain of the shell is increased to 0.97 . The increase in the plastic deformation on the cartridge leads to the decrease in the effective strain of the casing to 0.33 . In comparison with the case in Fig. 5, the effective stain of the casing is obviously decreased. The bulge height on the casing is decreased. The effect of different attached $\mathrm{Al}$ alloys on the bulge height of casing is summarized in Table 6. The attachment of 7075 aluminum alloy can reduce the bulge height to $3.46 \mathrm{~mm}$, i.e., $52.1 \%$ decrement compared to the case without attachment of soft metal. From Table 6, it can be seen that the increase in the yield stress of the attached soft metal can lead to the decrease in the bulge height. Figure 7 shows the relationship between the yield stress of the attached soft metal and the bulge height. This relationship

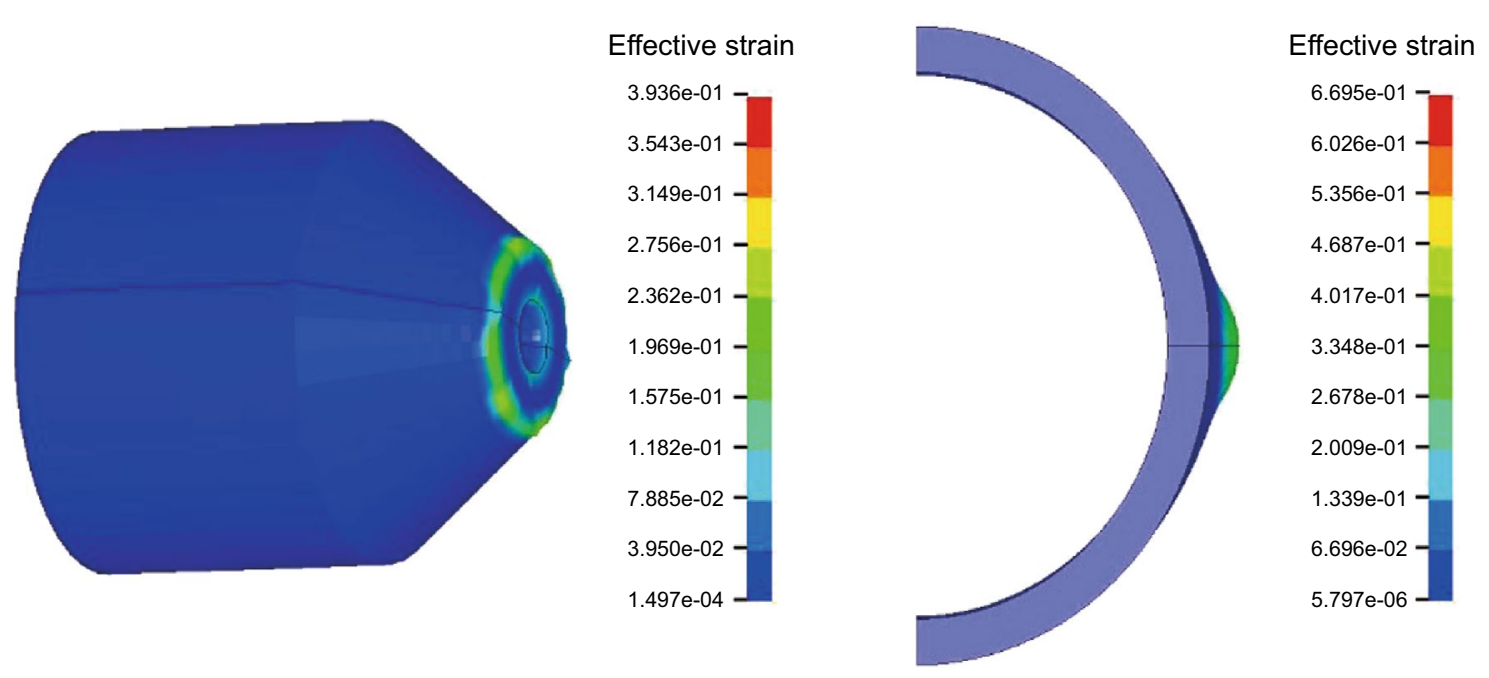

Fig. 5 Collision between the cartridge and the casing without soft metal 

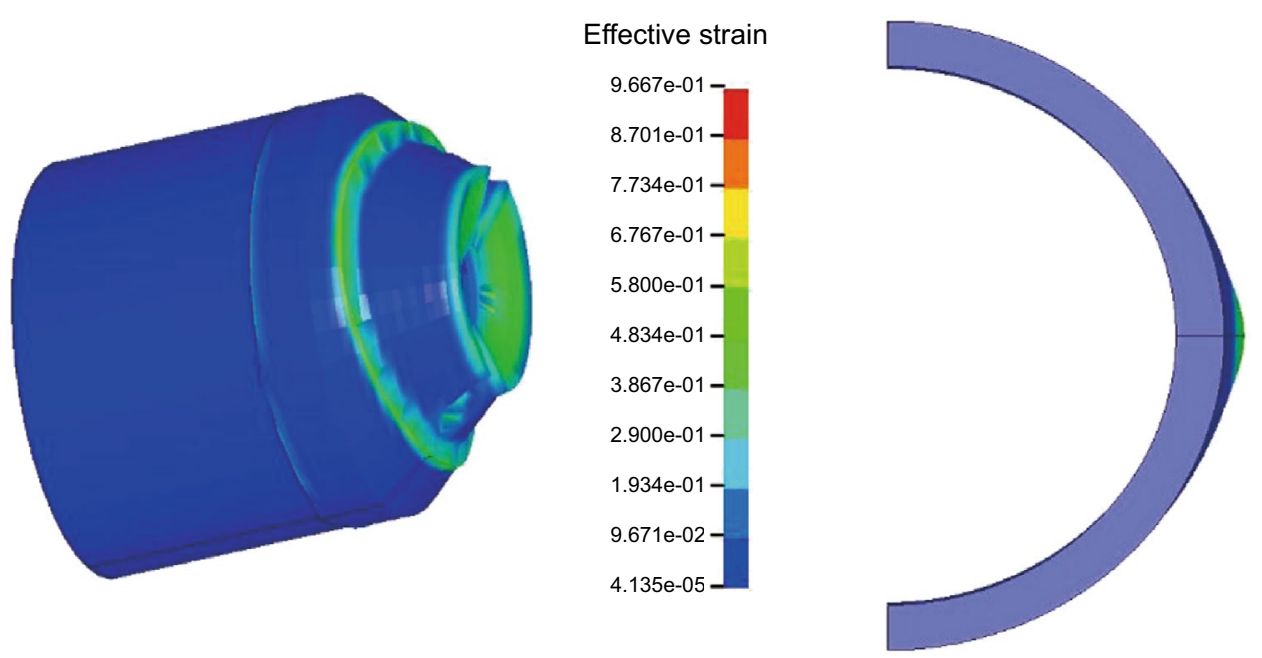

Effective strain

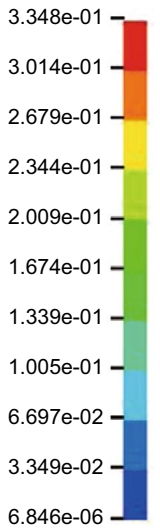

Fig. 6 Collision between the cartridge with addition of AA6061 and the casing

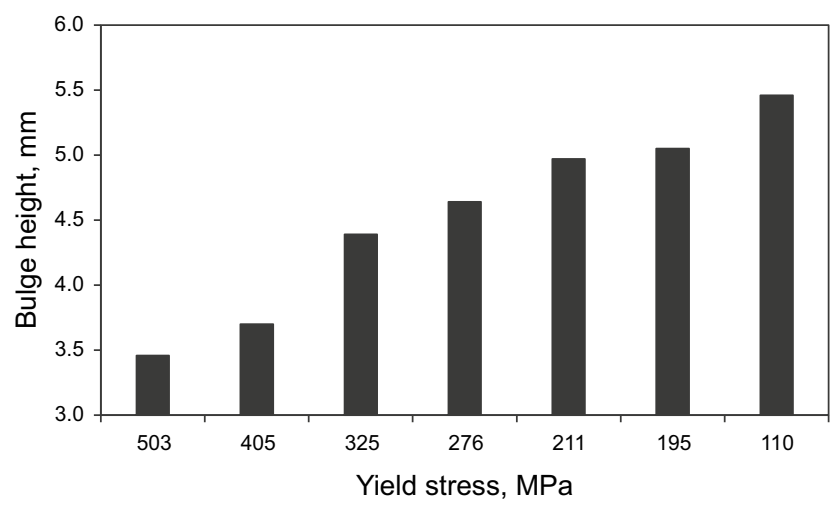

Fig. 7 Relationship between yield stress of attached aluminum and bulge height can be explained by the energy balance. The increases of the stress and strain can lead to the increase in the energy dissipations on the cartridge.

When a layer of AZ80A-T5 magnesium alloy is attached on the cartridge, as shown in Fig. 8, the effective strain of the shell is increased to 0.97 . Meanwhile, the effective strain of the casing is 0.36. In comparison with the case in Fig. 5, the effective stain of the casing is obviously decreased. However, the effective strain is slightly increased from 0.33 to 0.36 in comparison with Fig. 6 . The effect of different attached $\mathrm{Mg}$ alloys on the bulge height on casing is summarized in Table 7 and Fig. 9. 36.6\% decrement can be found when the AZ61A-F is attached. In the current case, the bulge height on the casing is $4.58 \mathrm{~mm}$.
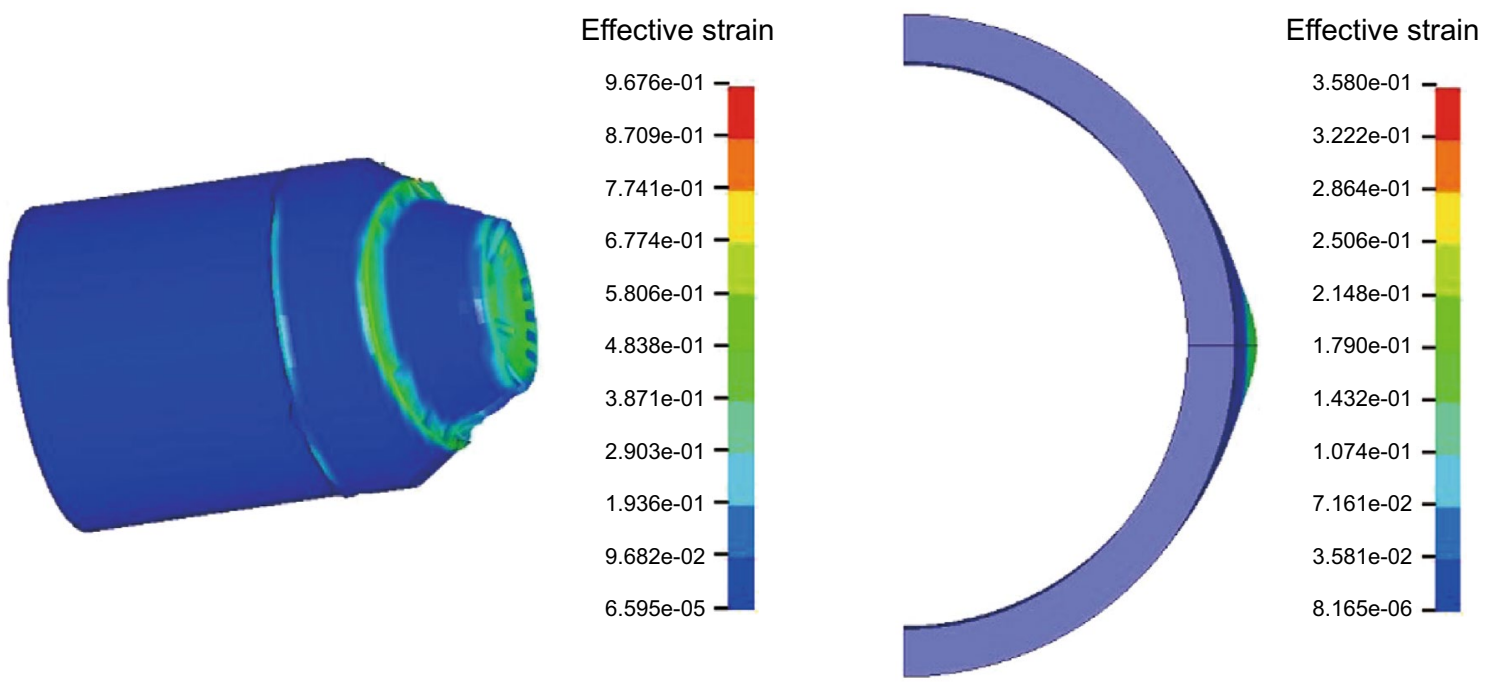

Fig. 8 Collision between the cartridge with addition of AZ80A-T5 and the casing 


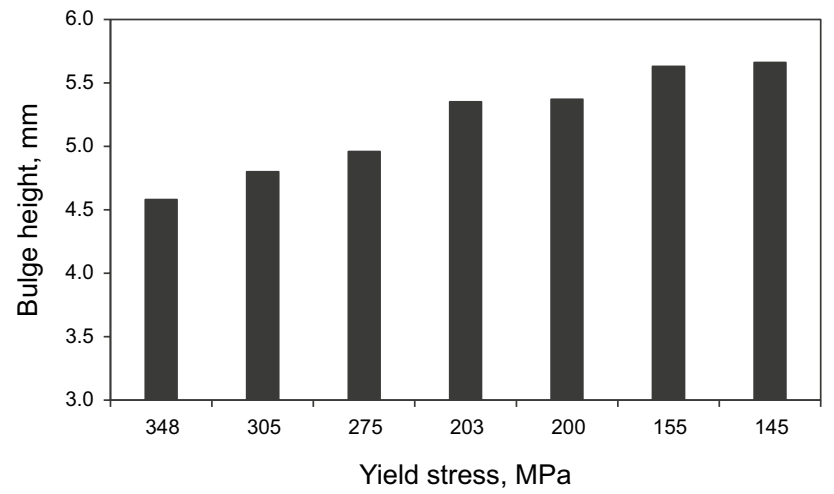

Fig. 9 Relationship between yield stress of attached magnesium and bulge height

Table 6 Effect of different attached Al alloys on the bulge height on casing

\begin{tabular}{llll}
\hline $\begin{array}{l}\text { Type of aluminum } \\
\text { alloy }\end{array}$ & $\begin{array}{l}\text { Yield stress, } \\
\mathrm{MPa}\end{array}$ & $\begin{array}{l}\text { Bulge height, } \\
\mathrm{mm}\end{array}$ & $\begin{array}{l}\text { Ratio of } \\
\text { decrement, } \\
\%\end{array}$ \\
\hline 7075 & 503 & 3.46 & 52.1 \\
7050 & 405 & 3.7 & 48.8 \\
2024 & 325 & 4.39 & 39.2 \\
6061 & 276 & 4.64 & 35.7 \\
5083 & 211 & 4.97 & 31.2 \\
5052 & 195 & 5.05 & 30 \\
1100 & 110 & 5.46 & 24.4 \\
\hline
\end{tabular}

Table 7 Effect of different attached Mg alloys on the bulge height on casing

\begin{tabular}{llll}
\hline $\begin{array}{l}\text { Type of magnesium } \\
\text { alloy }\end{array}$ & $\begin{array}{l}\text { Yield stress, } \\
\mathrm{MPa}\end{array}$ & $\begin{array}{l}\text { Bulge height, } \\
\mathrm{mm}\end{array}$ & $\begin{array}{l}\text { Ratio of } \\
\text { decrement, } \\
\%\end{array}$ \\
\hline AZ31B-F & 200 & 5.37 & 25.6 \\
AZ31B-H24 & 203 & 5.35 & 25.9 \\
AZ31B-O & 145 & 5.66 & 21.6 \\
AZ61A-F & 348 & 4.58 & 36.6 \\
AZ80A-T5 & 275 & 4.96 & 31.3 \\
ZK60A-T5 & 305 & 4.8 & 33.5 \\
ZM21-F & 155 & 5.63 & 22 \\
\hline
\end{tabular}

As summarized in Tables 6 and 7, the lowest bulge height can be obtained by use of 7075 aluminum alloy. The bulge height can be reduced by $52.1 \%$. The effect of AZ31B-O on bulge height is the smallest. It can only reduce the bulge height by $21.6 \%$. From the obtained results, it can be seen that the increase in the yield limit of the attached soft metal selected in current work can be beneficial to reduce the maximum bulge height. In similar yield stress, aluminum alloys show higher performance to reduce the bulge height on the casing in comparison with magnesium alloys.

When the jet penetrates the casing, the jet can be treated as a rigid body due to the high speed of the jet. Burr is formed on the casing in this collision. For the reuse of the perforating gun, the burr height must be small enough. The collision between the jet and the casing is completed within $8 \mu \mathrm{s}$. Moreover, the length size of jet is not a factor affecting the results in collision simulation because the jet in high velocity can be treated as rigid body (Xing et al. 2020). So, the state of tip jet at $8 \mathrm{~s}$ is used to be the rigid body in the simulation of the collision between the jet and the casing. The geometric parameters of the blind holes on the casing can be important factor to affect the burr heights. When the radius of the blind hole $(R)$ on DP36RDX25-2 perforating gun is $15.875 \mathrm{~mm}$ and the thickness of the blind hole $(t)$ is $9.7 \mathrm{~mm}$, the average burr height is $1.70 \mathrm{~mm}$ as shown in Fig. 10, which is smaller than the threshold in the design, i.e., $3 \mathrm{~mm}$. When the radius of the blind hole is increased to $20 \mathrm{~mm}$ as shown in Fig. 11, the average burr height is decreased to $1.204 \mathrm{~mm}$. When the thickness of the blind hole is decreased to $7.7 \mathrm{~mm}$ as shown in Fig. 12, the average burr height is increased from 1.7 to $2.76 \mathrm{~mm}$. This means that the increase in the radius or the decrease in the thickness of the blind hole is beneficial to control the burr height formed in the collision between the jet and the casing.

The effect of the liner angle on the penetration width is shown in Fig. 13. When the penetration hole is formed, the figure is sufficient to provide the studied penetration width. So, the initial stage of the penetration is used for comparison to reduce computational cost. With the increase in the liner angle, the penetration width is increased. More cases are summarized in Table 8. It reveals that smaller liner angle leads to narrower penetration width. The observation is fitted well with the experimental one (Shvetsov et al. 2011). The penetration width is a function of the maximum jet velocity,

$W=3260 e^{-1.529 v}$

where $W$ is the penetration width $(\mathrm{mm})$ and $v$ is the velocity of the jet $(\mathrm{km} / \mathrm{s})$.

\section{Conclusions}

The structures and the performance of the perforating gun and the perforator are studied numerically in the paper. The effect of different liner angles on the formation of the shaped charge jet and the penetration of the jet into the concrete target is considered via the adaptive re-meshing technique 

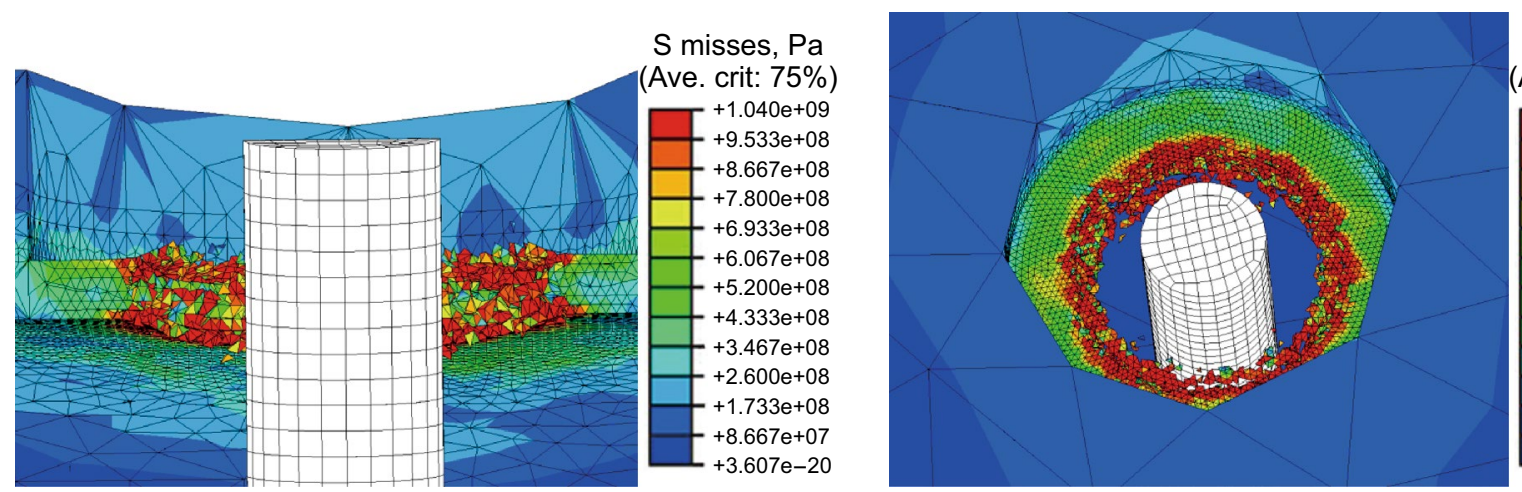

$S$ misses, $\mathrm{Pa}$

Ave. crit: $75 \%$ )

$+\begin{array}{r}+1.040 \mathrm{e}+09 \\ +9.533 \mathrm{e}+08\end{array}$

$+9.533 \mathrm{e}+08$

$+8.667 \mathrm{e}+08$
$+7.800 \mathrm{e}+08$

$+6.933 e+08$

$+6.067 \mathrm{e}+08$

$+5.200 \mathrm{e}+08$

$+4.333 e+08$

$+3.467 \mathrm{e}+08$

$+2.600 \mathrm{e}+08$

$+1.733 e+08$

$+8.667 \mathrm{e}+07$

$+3.607 \mathrm{e}-20$

Fig. 10 Collision between the jet and the casing when $R=15.875 \mathrm{~mm}$ and $t=9.7 \mathrm{~mm}$

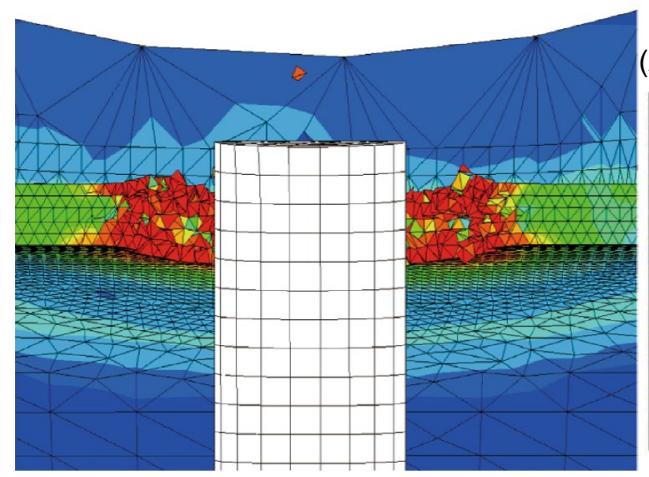

$\mathrm{S}$ misses, $\mathrm{Pa}$ (Ave. crit: 75\%)
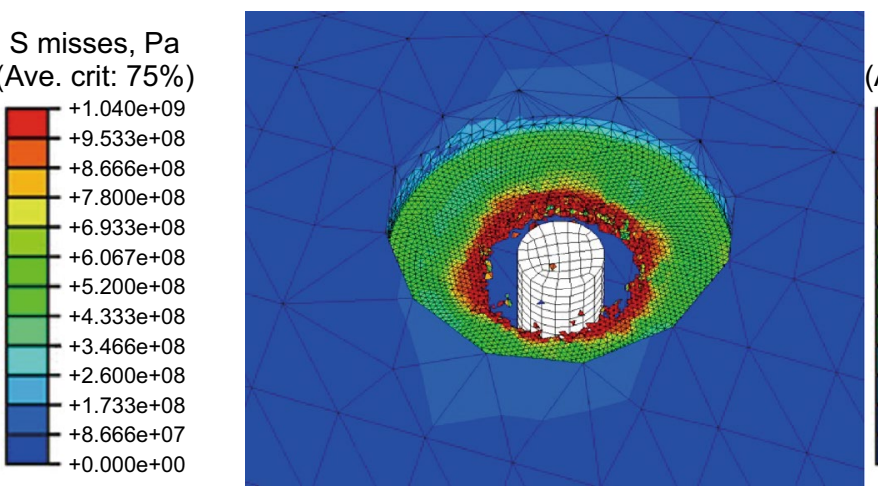

$\mathrm{S}$ misses, $\mathrm{Pa}$

Ave. crit: $75 \%$ )

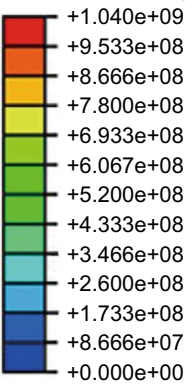

Fig. 11 Collision between the jet and the casing when $R=20 \mathrm{~mm}$ and $t=9.7 \mathrm{~mm}$

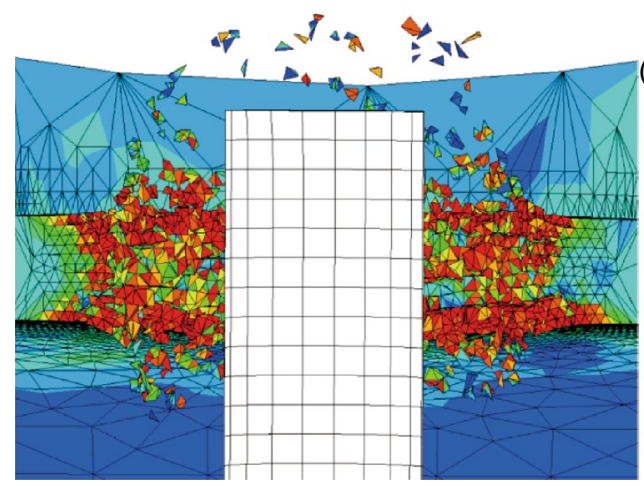

$\mathrm{S}$ misses, $\mathrm{Pa}$ (Ave. crit: $75 \%$ )
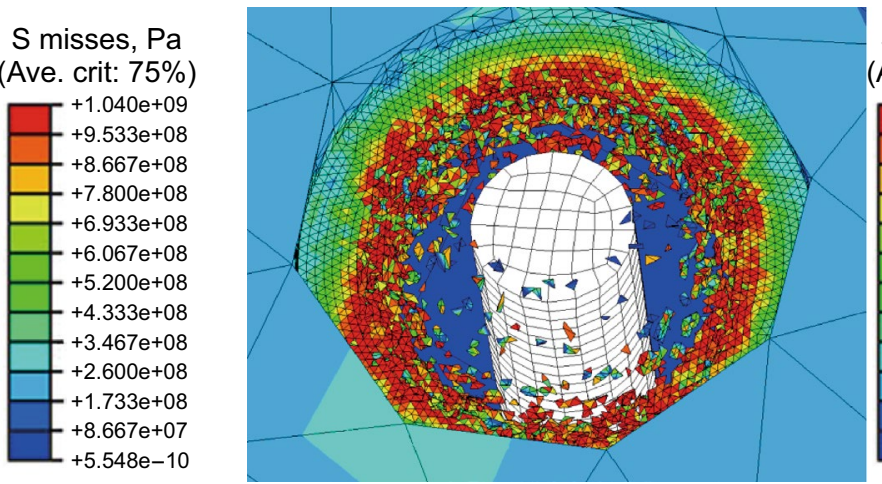

$\mathrm{S}$ misses, $\mathrm{Pa}$

Ave. crit: $75 \%$ )

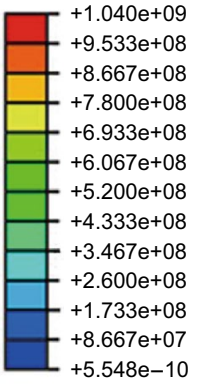

Fig. 12 Collision between the jet and the casing when $R=15.875 \mathrm{~mm}$ and $t=7.7 \mathrm{~mm}$

and ALE method. The influence of the soft metal layer on the bulge of the casing is studied. The burr of the blind hole is also studied. The current work can be useful for the design of the reusable perforating gun. The obtained results are summarized as follows:

1 Shaped charge jet is initially formed in the center of the shaped charge liner, and then, the material of the liner is driven to the centerline of the liner by the detonation wave.

2 The attachment of a layer of soft metal to the cartridge of the perforator can be beneficial to control the bulge height formed by the collision between the cartridge and the casing.

3 With the increase in the yield stress of the attached soft metal, the dissipated energy on the cartridge can 


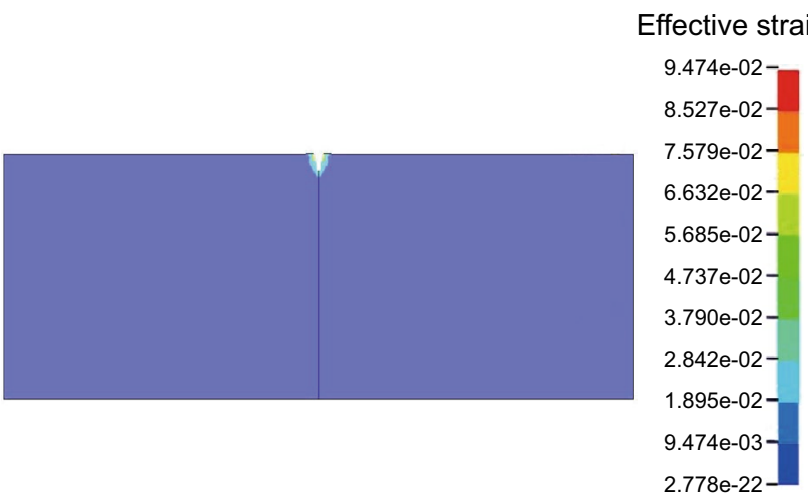

(a) $60^{\circ}$

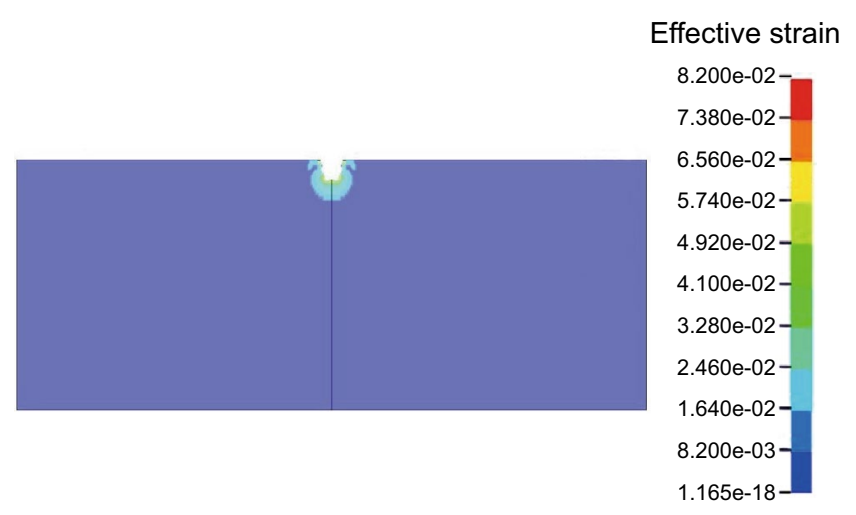

(c) $120^{\circ}$

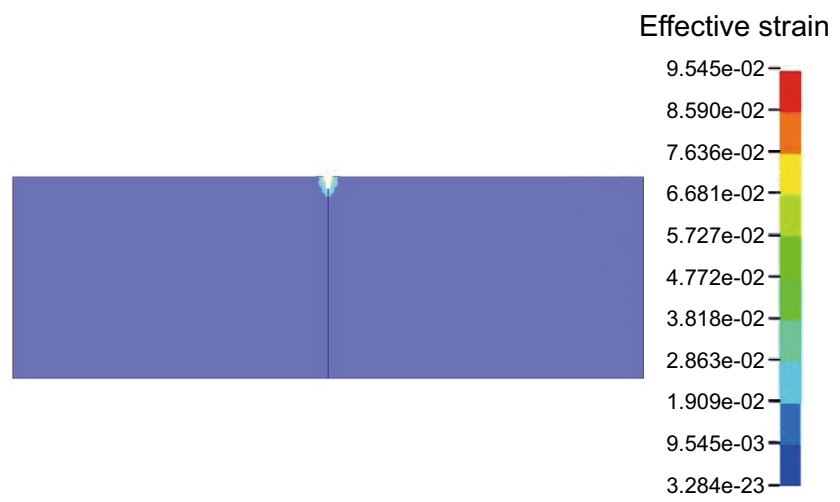

(b) $80^{\circ}$

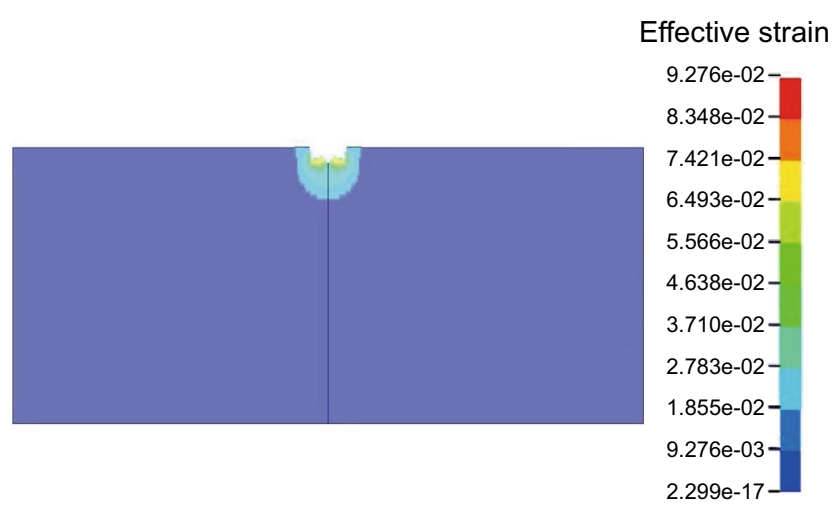

(d) $150^{\circ}$

Fig. 13 Collision of jet and concrete in different liner angles

be increased and the bulge height on the casing can be decreased.

4 The increase in the radius or the decrease in the thickness of the blind hole is beneficial to control the burr

Table 8 Effect of different liner angles on jet velocity and penetration

\begin{tabular}{llc}
\hline Liner angle, $^{\circ}$ & $\begin{array}{l}\text { Maximum of jet velocity, } \\
\mathrm{m} / \mathrm{s}\end{array}$ & $\begin{array}{l}\text { Penetration } \\
\text { width, mm }\end{array}$ \\
\hline 40 & 4911 & 2.35 \\
50 & 4456 & 2.76 \\
60 & 4236 & 3.55 \\
70 & 4115 & 4.70 \\
80 & 3957 & 7.29 \\
90 & 3857 & 9.41 \\
100 & 3777 & 14.10 \\
110 & 3617 & 18.80 \\
120 & 3421 & 19.76 \\
130 & 3346 & 21.65 \\
140 & 3144 & 23.45 \\
150 & 2967 & 27.88 \\
\hline
\end{tabular}

height formed in the collision between the jet and the casing.

5 With the increase in the liner angle, the penetration width is increased. An exponential function can be found between the penetration width and the liner angle.

Acknowledgements This work was financially supported by the National Natural Science Foundation of China (11572074) and Liaoning Provincial Natural Science Foundation (2019-KF-05-07).

Open Access This article is licensed under a Creative Commons Attribution 4.0 International License, which permits use, sharing, adaptation, distribution and reproduction in any medium or format, as long as you give appropriate credit to the original author(s) and the source, provide a link to the Creative Commons licence, and indicate if changes were made. The images or other third party material in this article are included in the article's Creative Commons licence, unless indicated otherwise in a credit line to the material. If material is not included in the article's Creative Commons licence and your intended use is not permitted by statutory regulation or exceeds the permitted use, you will need to obtain permission directly from the copyright holder. To view a copy of this licence, visit http://creativecommons.org/licenses/by/4.0/. 


\section{References}

Birkhoff G, MacDougall DP, Pugh EM. Explosives with lined cavities. J Appl Phys. 1948;19:563-82. https://doi. org/10.1063/1.1698173.

Dou YH, Cao YP, Li MF, Zhang YF. Experimental and theoretical study on the mechanical characteristics of perforated casings. Procedia Struct Integr. 2019;22:33-42. https://doi.org/10.1016/j. prostr.2020.01.005.

Du DF, Wang YY, Zhao YW, Sui PS, Xia X. A new mathematical model for horizontal wells with variable density perforation completion in bottom water reservoirs. Pet Sci. 2017;14:383-94. https ://doi.org/10.1007/s12182-017-0159-0.

Eichelberger RJ. Experimental test of the theory of penetration by metallic jets. J Appl Phys. 1956;27:63-8. https://doi. org/10.1063/1.1722198.

Eichelberger RJ, Pugh EM. Experimental verification of the theory of jet formation by charges with lined conical cavities. J Appl Phys. 1952;23:537-42. https://doi.org/10.1063/1.1702247.

Elshenawy T, Li QM. Influences of target strength and confinement on the penetration depth of an oil well perforator. Int J Impact Eng. 2013;54:130-7. https://doi.org/10.1016/j.ijimpeng.2012.10.010.

Gambirasio L, Rizzi E, Benson DJ. Eulerian simulations of perforating gun firing in air at atmospheric pressure: scallop geometry influence on design optimization. Acta Mech. 2017;228:991-1027. https://doi.org/10.1007/s00707-016-1750-y.

Guo TT, Ten HL, Ning JG. Theoretical model and numerical simulation of ceramic target against shaped charge jet penetration. Mater Res Innov. 2011;15:140-2. https://doi.org/10.1179/143307511X 12858956847750 .

Guo HG, Zheng YF, Yu QB, Ge C, Wang HF. Penetration behavior of reactive liner shaped charge jet impacting thick steel plates. Int J Impact Eng. 2019;126:76-84. https://doi.org/10.1016/j.ijimp eng.2018.12.005.

Hagoot J. An analytical model for predicting the productivity of perforated wells. J Pet Sci Eng. 2007;56:199-218. https://doi. org/10.1016/j.petrol.2006.09.001.

Karacan CO, Halleck PM. A fractal model for predicting permeability around perforation tunnels using size distribution of fragmented grains. J Pet Sci Eng. 2003;40:159-76. https://doi.org/10.1016/ S0920-4105(03)00136-0.

Lee WH. Oil well perforator design using 2D Eulerian code. Int J Impact Eng. 2002;27:535-59. https://doi.org/10.1016/S0734 $-743 \mathrm{X}(01) 00054-9$

Malygin AV, Proskuryakov EV, Sorokin MV. Shaped charge with an axial channel. J Appl Mech Tech Phys. 2011;52:347-51. https:// doi.org/10.1134/S0021894411030035.

Mareau C. A thermodynamically consistent formulation of the Johnson-Cook model. Mech Mater. 2020;143:103340. https://doi. org/10.1016/j.mechmat.2020.103340.

Meyers MA. Dynamic behavior of materials. New York: Wiley; 1994.

Molinari JF. Finite element simulation of shaped charges. Finite Elem Anal Des. 2002;38:921-36. https://doi.org/10.1016/S0168 -874X(02)00085-9.

Murphy MJ, Randers-Pehrson G, Kuklo RM, Rambur TA, Summers MA. Experiments and simulations of penetration into granite by an aluminum shaped charge. J Phys IV. 2003;110:603-8. https:// doi.org/10.1051/jp4:20020759.

Ott RE, Bell WT, Harrigan JW, Bell WT. Simple method predicts downhole shaped charge gun performance. SPE Prod Facil. 1994;9:171-8. https://doi.org/10.2118/27424-PA.

Shvetsov GA, Matrosov AD, Fedorov SV, Babkin AV, Ladov SV. Effect of external magnetic fields on shaped-charge operation. Int J Impact Eng. 2011;38:521-6. https://doi.org/10.1016/j.ijimp eng.2010.10.024.

Wan ZY, Zhang Z, Zhou X. Finite element modelling of grain growth by point tracking method in friction stir welding of AA6082T6. Int J Adv Manuf Technol. 2017;90:3567-74. https://doi. org/10.1007/s00170-016-9632-y.

Wang C, Ma T, Ning J. Experimental investigation of penetration performance of shaped charge into cement targets. Acta Mech Sin. 2008;24:345-9. https://doi.org/10.1007/s10409-008-0160-3.

Wang ZM, Wei JG, Zhang J, Gong B, Yan HY. Optimization of perforation distribution for horizontal wells based on genetic algorithms. Pet Sci. 2010;7:232-8. https://doi.org/10.1007/s1218 2-010-0027-7.

Xing HZ, Zhao J, Wu G, Ruan D, Dehkhoda S, Lu G, Zhang QB. Perforation model of thin rock slab subjected to rigid projectile impact at an intermediate velocity. Int J Impact Eng. 2020;139:103536. https://doi.org/10.1016/j.ijimpeng.2020.103536.

$\mathrm{Xu}$ WL, Wang $\mathrm{C}$, Chen DP. The jet formation and penetration capability of hypervelocity shaped charges. Int J Impact Eng. 2019;132:103337. https://doi.org/10.1016/j.ijimpeng.2019.10333 7.

Yan Y, Guan ZC, Yan WJ, Wang HT. Mechanical response and damage mechanism of cement sheath during perforation in oil and gas well. J Pet Sci Eng. 2020;188:106924. https://doi.org/10.1016/j. petrol.2020.106924.

Yu C, Li LZ, Huang YM. Studies on JWL equation of state of detonation product for aluminized explosive. Explos Shock Waves. 1999;19:274-9 (in Chinese).

Zhang XF, Qiao L. Studies on Jet Formation and penetration for a double-layer shaped charge. Combust Explos Shock Waves. 2011;47:241-8. https://doi.org/10.1134/S0010508211020134.

Zhang Z, Tan ZJ. A multi scale strategy for simulation of microstructural evolutions in friction stir welding of duplex titanium alloy. High Temp Mater Process. 2019;38:485-97. https://doi. org/10.1515/HTMP-2018-0148.

Zhang Z, Zhang HW. Solid mechanics-based Eulerian model of friction stir welding. Int J Adv Manuf Technol. 2014;72:1647-53. https:// doi.org/10.1007/S00170-014-5789-4.

Zhang Z, Wan ZY, Lindgren L-E, Tan ZJ, Zhou X. The simulation of precipitation evolutions and mechanical properties in friction stir welding with post-weld heat treatments. J Mat Eng Perform. 2017;26:5731-40. https://doi.org/10.1007/s11665-017-3069-9.

Zhao HF, Iblings D, Barykin L, Mehdi M. Plastic collapse behaviors of tubulars with recess patterns-application in hollow carrier perforating guns. ASCE-ASME J Risk Uncertain Eng Syst Part B Mech Eng. 2017;3:011004. https://doi.org/10.1115/1.4034660. 